\title{
Introduction to Special Issue on Traumatically Induced Pain: Assessing and Addressing Controversies
}

\author{
Michael E. Schatman • Robert J. Gatchel
}

Received: 29 June 2010 / Accepted: 7 July 2010 / Published online: 29 July 2010

(C) Springer Science+Business Media, LLC. 2010

This current Special Issue of Psychological Injury and Law focuses on traumatically induced pain and its medicolegal aspects. Because many individuals suffering from chronic pain have sustained their painful injuries as a result of trauma, it is common for them to become involved in litigation. As we know, chronic pain is a complex syndrome, characterized not only by persistent physical discomfort but also by a deleterious impact on numerous aspects of one's life (potentially including vocational, financial, social, sexual, recreational, and emotional functioning). Clearly, chronic pain is not merely an affliction of a body; rather, it should be conceptualized as an illness of the person (Schatman 2010a, b). This is not to suggest, however, that psychosocial factors are necessarily at the root of chronic pain (Melzack and Katz 2006). In fact, there is as much empirical evidence supporting chronic pain as the cause of psychopathology as there is supporting the primacy of psychosocial factors in the etiology of chronic pain (Gureje 2007; van't Land et al. 2010).

Rejecting the unidirectionality argument as explanatory of the psychosocial factor-pain experience relationship, mutual maintenance models hold that physiological, affective, and behavioral components of emotional distress maintain or exacerbate symptoms of pain and, similarly, that cognitive, affective, and behavioral components of chronic musculo-

M. E. Schatman $(\square)$

Pain and Addiction Study Foundation,

1215 120th Ave. NE, Suite 201,

Bellevue, WA 98005, USA

e-mail: headdock@comcast.net

R. J. Gatchel

Department of Psychology, College of Science,

The University of Texas at Arlington,

Arlington, TX, USA skeletal pain maintain or exacerbate symptoms of emotional distress. These models have been applied to, and empirically supported in, examinations of co-morbidities of chronic pain such as depression (Bair et al. 2003; Dworkin et al. 1992; von Korff and Simon 1996), post-traumatic stress disorder (PTSD) (Asmundson and Taylor 2006; Otis et al. 2003; Sharp and Harvey 2001), as well as general quality of life among chronic pain patients (Wahl et al. 2009). Relatively recent research has identified a shared biologic process underlying chronic pain and depression, in which serotonin and norepinephrine are involved in the dorsal raphe nucleus and locus ceruleus (Jann and Slade 2007). The identification of this shared mechanism lends additional support to the hypothesis of a bidirectional interaction between chronic pain and psychosocial factors. Also to be considered is the diathesis-stress model of psychopathology and chronic pain, which has ultimately developed into the dominant overarching theoretical perspective. This model, initially articulated by Gatchel and colleagues (Dersh et al. 2006, 2001, 2002; Gatchel 1991, 1996), assumes the presence of premorbid yet semi-dormant characteristics of the patient that exist prior to the onset of pain, which are then activated in response to the stress of the painful condition and its psychiatric sequelae. Moreover, the wide-ranging impact of pain becomes even more complex when injured parties choose to pursue litigation relating to their pain-producing injuries. Results of an early meta-analysis (Rohling et al. 1995), for example, suggested that receiving financial compensation was associated with a greater experience of pain and reduced treatment efficacy, with the authors positing causal attribution. However, subsequent reviews have questioned this validity of the proposed causal relationship (Kolbinson et al. 1996; Scholten-Peeters et al. 2003; Sterner and Gerdle 2004) or have suggested that it has not been adequately studied to presume that litigation has an impact on prognosis (Carroll et al. 2008). 
The emotional role of pain among traumatically injured patients is merely one of a myriad of controversial issues that arise within the field of psychological injury and law. With this in mind, the present Special Issue consists of seven articles written by thought-leaders in the field, each of which addresses a controversial area. Two of the articles report on empirical studies conducted by the authors, while others are reviews aimed at unraveling the complexities of the issues that are covered. The first article in this issue, written by Bruns, Mueller, and Warren, considers the laws and regulations mandating biopsychosocial treatment guidelines for workers' compensation injuries. Despite the formidable body of literature and numerous systematic reviews supporting the biopsychosocial approach to pain (Guzmán et al. 2001; Guzmán et al. 2002; Schonstein et al. 2003), its application is hardly universal in the USA and Canada (Schatman 2010a, b). Bruns and colleagues offer the term "biopsychosocial law" to describe the guidelines that are progressively being developed, noting that they do not necessarily fit into the traditional and established categories of medical or mental health laws under which clinicians and pain sufferers have operated. Rejecting Cartesian mind-body dualism, these biopsychosocial laws are the product of an emerging convergence of an empirically established evidence-basis, positions promoted by thought-leaders in professional societies, payor policies, and current legal regulations.

The next article is a philosophically as well as a scientifically based exposition written by Schatman and Sullivan that considers the impact of tort reform on the emotional and existential healing of traumatically injured chronic pain patients. In approximately one half of the USA, tort reform has limited non-economic awards and verdicts, resulting in the diminution of compensation for "pain and suffering." The authors consider numerous sequelae of traumatically induced chronic pain that contribute to human suffering, including PTSD, depression and anxiety, role/identity loss, maltreatment by a medical system generally inept in its management of chronic pain, and the negative manner in which personal injury victims are often treated by the legal system. Schatman and Sullivan make the argument that chronic pain sufferers have become psychologically and existentially "deconstructed" and that the act of limiting their abilities to receive awards commensurate with their global losses deprives personal injury victims of a critical vehicle for finding meaning in their suffering.

Another controversial medicolegal issue explored in this Special Issue is the misconception regarding the prevalence and meaning of malingering. Up to this point, the majority of the literature on malingering has emphasized the role of primary and secondary gain. In this issue, Howard, Kishino, Johnston, Worzer, and Gatchel acknowledge the potential for these gains in medicolegal cases but also note the potential impact of primary and secondary losses in perpetuating disability. Rather than looking at malingering as a simplistic, "black-or-white" issue (as has been the tendency in the medicolegal literature; Bianchini et al. 2005), the authors discuss alternative explanations for exaggeration of symptoms. Howard and colleagues note that the "enlightened" manner through which to consider malingering is a biopsychosocial one, considering it within the context of disability behavior. Different strategies for assessing malingering that have been proposed are critically examined, and the use of the Comprehensive Muscular Activity Profile (CMAP; Medical Technologies Unlimited 2008) is suggested due to its superior reliability compared with traditional, subjective self-report malingering assessment tools. The authors also address differential diagnoses from other DSM-IV disorders that are often misaken for malingering. They conclude their article with a note of caution regarding the deleterious impact on the claimant of misdiagnosing malingering.

In the next article, Gatchel, Kishino, and Minotti consider the three major components of behavior commonly utilized to assess pain, and the difficulties that develop when there is discordance among them. Issues relating to reliable operational definitions in self-report, overt patient behavior/ function, and physical indices are reviewed, and caution is given to automatically assuming that these components will necessarily be concordant or highly correlated. The authors suggest that a "stepwise approach" to assessment represents the best biopsychosocial approach that can be used to assess pain and note that the potential complex interactions among the constructs of pain, impairment, and disability can serve to make accurate assessment of pain arduous. Gatchel and colleagues' emphasis on the importance of taking a biopsychosocial approach to the assessment of pain complements the recommendation to consider malingering biopsychosocially in the previous article by Howard and colleagues.

The primacy of functional capacities in the medicolegal arena cannot be overlooked. As clinicians may make different judgments regarding malingering and pain itself, they may also demonstrate discordance in their judgments of functional capacities. The next article in this issue presents an empirical investigation of the validity and determinants of physiotherapists' assessments of whiplash victims' abilities to return to work following treatment. Scott and Sullivan utilize hierarchical regression analyses to determine that clinicians' judgments add unique variance to their return to work prediction beyond other predictive factors, finding that these judgments are particularly influenced by patients' reports of pain severity and treatment-related changes in pain levels. Interestingly, clinicians' judgments were determined to be the strongest 
predictor of return to work, although they accounted for only $12 \%$ of the variance. The authors also measured psychosocial functioning during the course of treatment. Like changes in physical functioning, changes in psychological variables were not significantly associated with return to work. In discussing limitations of their study, Scott and Sullivan note that their investigation was conducted in the Canadian no-fault system, and that their data may not necessarily generalize to a tort-based system. Nevertheless, their study is groundbreaking, making a significant contribution to our understanding of the impact of clinician judgments of functional capacities.

The impact of attorneys in determining adjustment outcomes for Workers' Compensation claimants has been studied previously (Butterfield et al. 1998; Chibnall et al. 2005; Tait et al. 1990), with the results of these investigations leading to the commonly held conception that attorney involvement in Workers' Compensation results in higher levels of pain, disability, and psychosocial distress. Additionally, there is empirical evidence that Workers' Compensation claimants are motivated to seek legal representation in response to their dissatisfaction with various aspects of the management of their cases by the insurer (Rudolph et al. 2002; Wickizer et al. 2004a, 2004b). In their article, Chibnall and Tait break new ground by addressing the combination of attorney retention and dissatisfaction, comparing claimant adjustment indicators both post-settlement and at long-term (average 72 months post-claim settlement) follow-up. The authors determined that claimants who retained attorneys due to their dissatisfaction differed significantly in terms of adjustment indicators, not only at the time of settlement but at longterm follow-up as well. From their findings, Chibnall and Tait conclude that the adversarial form of litigation may serve to augment disability, thereby potentially making the two factors of attorney retention and claimant dissatisfaction a "particularly toxic combination."

In the final article in this Issue, Duckworth and Iezzi take a novel approach to the development of disability following traumatic injury. They posit that it is not only the traumatic injury itself that results in disability, but the interplay of the physical and psychological injuries sustained by injury victims that contributes to the loss of function and quality of life among these individuals. This article parallels that by Schatman and Sullivan, noting that injury victims experience widespread disruptions of their lifestyles due to the manner in which physical injury serves as a catalyst for psychosocial losses - with the resulting stress serving to inhibit recovery. While Schatman and Sullivan opine that this process is likely to result in exacerbated suffering, Duckworth and Iezzi focus more specifically on its contribution to the development of PTSD, depression, and substance use disorders. Finally, the authors present a number of models, including one that they developed, that purport to identify those factors that are most relevant to transition from physical injury to functional impairment to disability.

In conclusion, as a whole, the articles in this Special Issue represent an outstanding and informative sampling of the very controversial issues associated with the intersection of traumatically induced pain and the law. Because the controversies are myriad and new controversies continue to develop, we anticipate additional special issues on the subject in the future. As the medical and legal systems change, society's overall consideration and approach to traumatically induced pain and related legal issues will likely go through metamorphoses. While this issue represents the mere "tip of the iceberg," we hope that its contents inspire thought among psychologists and attorneys that will ultimately lead to a much-needed paradigmatic revision in the manner in which the medicolegal system treats trauma victims suffering from pain.

\section{References}

Asmundson, G. J. G., \& Taylor, S. (2006). PTSD and chronic pain: Cognitive behavioral perspectives and practical implications. In G. Young, A. W. Kane, \& K. Nicholson (Eds.), Psychological knowledge in court: PTSD, pain, and TBI (pp. 225-241). New York: Springer.

Bair, M. J., Robinson, R. L., Katon, W., \& Kroenke, K. (2003). Depression and pain comorbidity. Archives of Internal Medicine, 163, 2433-2445.

Bianchini, K. J., Greve, K. W., \& Glynn, G. (2005). On the diagnosis of malingered pain-related disability: Lessons from cognitive malingering research. The Spine Journal, 5, 404-417.

Butterfield, P. G., Spencer, P. S., Redmond, N., Feldstein, A., \& Perrin, N. (1998). Low back pain: predictors of absenteeism, residual symptoms, functional impairment, and medical costs in Oregon workers' compensation recipients. American Journal of Industrial Medicine, 34, 559-567.

Carroll, L. J., Hogg-Johnson, S., van der Velde, G., Haldeman, S., Holm, L. W., Carragee, E. J., et al. (2008). Course and prognostic factors for neck pain in the general population: Results of the Bone and Joint Decade 2000-2010 Task Force on Neck Pain and Its Associated Disorders. Spine, 33(Suppl. 4), S75-S82.

Chibnall, J. T., Tait, R. C., Andresen, E. M., \& Hadler, N. M. (2005). Race and socioeconomic differences in post-settlement outcomes for African American and Caucasian Workers' Compensation claimants with low back injuries. Pain, 114, 462-472.

Dersh, J., Gatchel, R. J., Mayer, T., Polatin, P., \& Temple, O. (2006). Prevalence of psychiatric disorders in patients with chronic disabling chronic spinal disorders. Spine, 31, 1156-1162.

Dersh, J., Gatchel, R. J., \& Polatin, P. (2001). Chronic spinal disorders and psychopathology: Research findings and theoretical considerations. The Spine Journal, 1, 88-94.

Dersh, J., Polatin, P., \& Gatchel, R. J. (2002). Chronic pain and psychopathology: Research findings and theoretical considerations. Psychosomatic Medicine, 64, 773-786.

Dworkin, S. F., Von Korff, M. R., \& Leresche, L. (1992). Epidemiologic studies of chronic pain: A dynamic ecologic perspective. Annals of Behavioral Medicine, 14, 3-11. 
Gatchel, R. J. (1991). Early development of physical and mental deconditioning in painful spinal disorders. In T. G. Mayer, V. Mooney, \& R. J. Gatchel (Eds.), Contemporary conservative care for painful spinal disorders (pp. 278-289). Philadelphia: Lea \& Febiger.

Gatchel, R. J. (1996). Psychological disorders and chronic pain: Cause and effect relationships. In R. J. Gatchel RJ \& D. C. Turk (Eds.), Psychological approaches to pain management: A practitioner's handbook (pp. 33-52). New York: Guilford.

Gureje, O. (2007). Psychiatric aspects of pain. Current Opinion in Psychiatry, 20, 42-46.

Guzmán, J., Esmail, R., Karjalainen, K., Malmivaara, A., Irvin, E., \& Bombardier, C. (2001). Multidisciplinary rehabilitation for chronic low back pain: A systematic review. British Medical Journal, 322, 1511-1516.

Guzmán, J., Esmail, R., Karjalainen, K., Malmivaara, A., Irvin, E., \& Bombardier, C. (2002). Multidisciplinary bio-psycho-social rehabilitation for chronic low back pain. Cochrane Database of Systematic Review, CD000963.

Jann, M. W., \& Slade, J. H. (2007). Antidepressant agents for the treatment of chronic pain and depression. Pharmacotherapy, 27, 1571-1587.

Kolbinson, D. A., Epstein, J. B., \& Burgess, J. A. (1996). Temporomandibular disorders, headaches, and neck pain following motor vehicle accidents and the effect of litigation: Review of the literature. Journal of Orofacial Pain, 10, 101-125.

Medical Technologies Unlimited. (2008). Comprehensive muscular activity profile. http://www.med-tek.com. Accessed 8 December, 2008.

Melzack, R., \& Katz, J. (2006). Pain in the 21st century: The neuromatrix and beyond. In G. Young, A. W. Kane, \& K. Nicholson (Eds.), Psychological knowledge in court: PTSD, pain, and TBI (pp. 129-148). New York: Springer.

Otis, J. D., Keane, T. M., \& Kerns, R. D. (2003). An examination of the relationship between chronic pain and post-traumatic stress disorder. Journal of Rehabilitation Research and Development, 40, 397-405.

Rohling, M. L., Binder, L. M., \& Langhinrichsen-Rohling, J. (1995). Money matters: A meta-analytic review of the association between financial compensation and the experience and treatment of chronic pain. Health Psychology, 14, 537-547.

Rudolph, L., Dervin, K., Cheadle, A., Maizlish, N., \& Wickizer, T. M. (2002). What do injured workers think about their medical care and outcomes after work injury? Journal of Occupational and Environmental Medicine, 44, 425-434.

Schatman, M. E. (2010a). Interdisciplinary chronic pain management: Perspectives on history, current status, and future viability. In J.
C. Ballantyne, J. P. Rathmell, \& S. M. Fishman (Eds.), Bonica's management of pain (4th ed., pp. 1523-1532). Philadelphia: Lippincott, Williams \& Wilkins.

Schatman, M. E. (2010b). Psychological assessment of maldynic pain: The need for a phenomenological approach. In J. Giordano (Ed.), Maldynia: Inter-disciplinary perspectives on the illness of chronic pain. New York: Informa Healthcare. in press.

Scholten-Peeters, G. G., Verhagen, A. P., Bekkering, G. E., van der Windt, D. A., Barnsley, L., Oostendorp, R. A., et al. (2003). Prognostic factors of whiplash-associated disorders: A systematic review of prospective cohort studies. Pain, 104, 303-322.

Schonstein, E., Kenny, D. T., Keating, J., \& Koes, B. W. (2003). Work conditioning, work hardening and functional restoration for workers with back and neck pain. Cochrane Database of Systematic Reviews, CD001822.

Sharp, T. J., \& Harvey, A. G. (2001). Chronic pain and posttraumatic stress disorder: Mutual maintenance? Clinical Psychology Review, 21, 857-877.

Sterner, Y., \& Gerdle, B. (2004). Acute and chronic whiplash disorders: A review. Journal of Rehabilitation Medicine, 36, 193-209.

Tait, R. C., Chibnall, J. T., \& Richardson, W. D. (1990). Litigation and employment status: Effects on patients with chronic pain. Pain, $43,37-46$.

van't Land, H., Verdurmen, J., ten Have, M., van Dorsselaer, S., Beekman, A., \& de Graaf, R. (2010). The association between arthritis and psychiatric disorders: Results from a longitudinal population-based study. Journal of Psychosomatic Research, 68 , 187-193.

Von Korff, M., \& Simon, G. (1996). The relationship between pain and depression. The British Journal of Psychiatry, 168(Suppl. 30), 101-108.

Wahl, A. K., Rustøen, T., Rokne, B., Lerdal, A., Knudsen, Ø., Miaskowski, C., et al. (2009). The complexity of the relationship between chronic pain and quality of life: A study of the general Norwegian population. Quality of Life Research, 18, 971-980.

Wickizer, T. M., Franklin, G., Fulton-Kehoe, D., Turner, J. A., Mootz, R., \& Smith-Weller, T. (2004b). Patient satisfaction, treatment experience, and disability outcomes in a populationbased cohort of injured workers in Washington state: implications for quality improvement. Health Services Research, 39, $727-748$.

Wickizer, T. M., Franklin, G., Turner, J. A., Fulton-Kehoe, D., Mootz, R., \& Smith-Weller, T. (2004a). Use of attorneys and appeal filing in the Washington state workers' compensation program: Does patient satisfaction matter? Journal of Occupational and Environmental Medicine, 46, 331-339. 